\title{
Effects of feedback, competitor's gender, and locus of control on reaction time of females
}

\author{
JOHN L. ALLEN, SHERIENE E. SAADATI, and CATHERINE L. CLEMENTS \\ Point Loma College, San Diego, California \\ and \\ DANIEL D. MORIARTY, JR. \\ University of San Diego, San Diego, California
}

\section{(M. Ray Denny, Sponsor)}

\begin{abstract}
In Experiment 1, 32 females were randomly assigned to four groups, differing in sex of competitor and feedback condition (winning or losing). Each subject competed individually. Following five discriminative reaction time trials, the subject received feedback and was given five more trials. All subjects improved significantly following feedback except those females competing with a male and winning. In Experiment 2, 40 female subjects were assigned to four groups, differing in locus of control (internal or external) and feedback condition. Each of these subjects competed with a male. Both internal-control groups improved significantly following feedback. Externalcontrol subjects who were told they were losing improved dramatically $(p<.0005)$; however, external-control subjects who were told they were winning did not improve significantly.
\end{abstract}

Horner (1969) asked male and female college students to read a projective story involving a male or a female who was at the top of a medical school class and to complete the story. Sixty-five percent of the story completions about the female done by female subjects involved negative images. Horner suggested that when an intelligent female is placed in an achievement-oriented situation, she may experience a conflict between her need to achieve and the societal expectation that she conform to sex role standards. She referred to this phenomenon as the "motive to avoid success." Other studies have demonstrated lower performance by females competing with a male than by those competing with a female (Allen \& Boivin, 1976; Horner, 1974; Karabenick \& Marshall, 1974). The present study investigated not only the effects of gender of competitor, but also type of feedback (winning or losing).

\section{EXPERIMENT 1}

\section{Method}

Subjects. Thirty-two female volunteers were recruited from introductory psychology courses and randomly assigned to one of four groups: competing with a male and winning (Group MW), competing with a male and losing (Group ML), competing with a female and winning (Group FW), and competing with a female and losing (Group FL).

Apparatus. Discriminative reaction times were measured by connecting a Lafayette Visual Choice Reaction Time Apparatus to a Thornton DEC-120 counter timer. An audiocassette deck with an auxiliary speaker was used to present instructions and a ready signal.

Please address correspondence to Daniel Moriarty, Department of Psychology, University of San Diego, San Diego, CA 92110.
Procedure. When a subject arrived, she was directed to a room in which either a male or a female confederate was waiting. They were introduced and told that they would be competing against one another for the fastest reaction time on identical apparatuses in separate rooms. After the subject was taken to her room and seated in front of the apparatus, the confederate was dismissed. The experimenter returned to a room adjacent to that in which the subject was to be tested. Taperecorded instructions were then presented to her. She was informed that a ready tone would be presented, which was her signal to place her index finger at a specified place on the apparatus. She was told that within $5 \mathrm{sec}$, one of the four colored lights would come on, and she was to press the corresponding button as fast as possible. She was told that following two practice trials, five competition trials would be given, and at the end of those trials she would be told if she was winning or losing. Five more trials would then be given and the winner announced. Presentation time following the ready signal (3-5 sec) and the order of light presentation were both randomized.

\section{Results and Discussion}

Median reaction times were calculated for each subject on the first and last five trials. Two-factorial (sex $\times$ feedback) analyses of variance revealed no significant between-groups main or interaction effects for either the first or second five trials. However, $t$ tests for matched groups did reveal significant within-subject differences when group means for the first and the second five trials were compared. Groups ML, FL, and FW showed significant improvement in the last five trials $[t(7)=2.18$, $p<.05 ; t(7)=2.09, p<.05 ; t(7)=2.01, p<.05$, respectively]. Group MW did not show significant improvement $[t(7)=1.36, p>.05]$.

Motive to avoid success was not revealed in the present study. In fact, females competing with males on the first five trials (prior to feedback) actually demonstrated a faster mean median reaction time $(M=.604 \mathrm{sec})$ than 
females competing with females $(M=.658 \mathrm{sec})$. Performance improved significantly in the last five trials when females competed with females in both feedback conditions, but females competing with males improved only when told they were losing. Females competing with males did not demonstrate significant improvement when they were told they were winning.

\section{EXPERIMENT 2}

Individuals who perceive that the presentation of reinforcement is due to chance, luck, or other people have an external locus of control, and those who perceive that the presentation is primarily contingent on their own behavior have an internal locus of control (Rotter, 1966). Although studies have been conducted on the role of locus of control in competitive situations (Aguglia \& Sapienza, 1984; Henderson \& Hennig, 1979; Nowicki, 1982; Nowicki, Duke, \& Crouch, 1978), none has considered within-subject changes in performance related to feedback conditions. The present experiment sought to determine the role that locus of control might play in the failure of Group MW to reach or approach significant improvement following feedback.

\section{Method}

Subjects. The Rotter Scale was administered to female students in freshman-level introduction to psychology courses. As in previous studies (Bolen \& Torrance, 1978; Lotsof \& Steinke, 1973), those students who scored in the top third (externals) and bottom third (internals) of the classes were asked to participate in this experiment. Twenty externals (E) and 20 internals (I) were used as subjects. Those in each category were randomly assigned to equal-sized groups and told that they were either winning (Groups EW and IW) or losing (Groups EL and IL), thus completing a $2 \times 2$ factorial design. As in Experiment 1 , subjects were told that they were competing, but the confederate was always a male.

Apparatus. The same discriminative reaction time apparatus used in Experiment 1 was used in this experiment.

Procedure. With the exception of assigning subjects to groups on the basis of Rotter Scale scores and using only male confederates, the procedure in this experiment was identical to that of Experiment 1.

\section{Results and Discussion}

Median reaction times were calculated for each subject on the first and last five trials. Two-factorial (locus of control $\times$ feedback) analyses of variance revealed no significant between-groups main or interaction effects for the first or second five trials. However, $t$ tests for matched groups did reveal significant within-subject differences when group means for the first and the second five trials were compared. Groups IW, IL, and EL showed significant improvement $[t(9)=1.90, p<.05 ; t(9)=2.46$, $p<.05 ; t(9)=7.00, p<.0005$, respectively]. Group EW did not show significant improvement $[t(9)=$ $1.18, p>.05]$.

The mean median reaction time on the first five trials in the present study $(M=.603 \mathrm{sec})$ is nearly identical to that obtained in Experiment 1 when females were told they were competing with a male $(M=.604 \mathrm{sec})$. Also, as in Experiment 1, the "winning" feedback to the present experiment's external group did not result in significant im- provement $(M=.594 \mathrm{sec}$ on the first five trials, and $M$ $=.575 \mathrm{sec}$ on the last five). However, this failure to show significant improvement was only observed in Group EW. Group EL demonstrated sizable improvement in performance $(M=.597 \mathrm{sec}$ to $M=.527 \mathrm{sec})$.

The significant improvement of Group IW in this study suggests that the failure of Group MW in Experiment 1 to approach significant improvement was due to the external-control subjects in the group.

\section{GENERAL DISCUSSION}

In both experiments females who were told they were competing with males demonstrated faster mean median reaction times than females who were told they were competing with females in Experiment 1. This is the opposite of what would be predicted by the motive to avoid success interpretation and is in contrast to previous studies. Perhaps increased female involvement in occupations previously dominated by males has modified societal expectations and reduced the conflict that led to the motive to avoid success. In any event, a change in performance seems to have taken place in recent years.

These results appear to be consistent with a locus of control interpretation. External-control females may have been subject to extremes of motivation, having already received reinforcement from the experimenter in the winning condition, and fearing aversive feedback from others in the losing condition. Internal-control females would be expected to show more consistent performance, since they would have evaluated their performance by their own standards in both conditions. Further research is needed to determine the possible role of locus of control in male competitive reaction time.

\section{REFERENCES}

Aguglia, E., \& SaPIEnZa, S. (1984). Locus of control according to Rotter's S.R.I. in volleyball players. International Journal of Sport Psychology, 15, 250-258.

Allen, J. L., \& Boivin, M. R. (1976). "Women's will to fail" in a disjunctive reaction time competitive task. Bulletin of the Psychonomic Society, 8, 401-402.

Bolen, L. M., \& Torrance, E. P. (1978). The influence on creative thinking of locus of control, cooperation, and sex. Journal of Clinical Psychology, 34, 903-907.

Henderson, R. W., \& HeNNIG, H. (1979). Relationships among cooperation-competition and locus of control in social and academic situations among children in traditional and open classrooms. Contemporary Educational Psychology, 4, 121-131.

Horner, M. S. (1969, November). "Fail: Bright women."' Psychology Today, pp. 36-38.

HoRNER, M. S. (1974). The measurement and behavioral implications of fear of success in women. In J. W. Atkinson \& J. O. Raynor (Eds.), Motivation and achievement (pp. 91-117). Washington, DC: Winston.

Karabenick, S. A., \& Marshall, J. M. (1974). Performance of females as a function of fear of success, fear of failure, type of opponent, and performance-contingent feedback. Journal of Personality, 42, 220-237.

Lotsof, E. J., \& STEINKE, J. (1973). Internal-external control, divergent thinking and levels of abstractness. Psychological Reports, 32, 1035-1041.

NowICKI, S. (1982). Competition-cooperation as a mediator of locus of control and achievement. Journal of Research in Personality, 16, 157-164.

Nowicki, S., Duke, M. P., \& Crouch, M. D. (1978). Sex differences in locus of control and performance under competitive and cooperative conditions. Journal of Educational Psychology, 70, 482-486.

ROTTER, J. B. (1966). Generalized expectations for internal versus external control of reinforcement. Psychological Monographs, 80(1, Whole No. 609).

(Manuscript received for publication September 14, 1987.) 